\title{
PENGARUH KEPEMIMPINAN KEPALA SEKOLAH, DISIPLIN KERJA, TERHADAP KINERJA GURU SD DI WILAYAH KECAMATAN KLATEN SELATAN KABUPATEN KLATEN
}

\author{
Tukiyo \\ Universitas Widya Dharma Klaten \\ tukiyo@unwidha.ac.id
}

\begin{abstract}
ABSTRAK
Penelitian ini di latarbelakangi oleh bagaimana pengaruh kepemimpinan kepala sekolah, disiplin kerja , terhadap kinerja guru SD di wilayah kecamatan klaten selatan kabupaten klaten Metode dalam penelitian ini Metode yang digunakan dalam penelitian ini adalah survey.. Sasaran dalam penelitian ini adalah guru-guru SD Negeri dan SD Swasta yang mengajar di wilayah Kecamatan Klaten Selatan, Kabupaten Klaten. Teknik analisis pada penelitian ini menggunakan uji asumsi klasik, metode rergresi linier berganda, uji hipotesis dan uji koefisien determinasi Hasil penelitian yaitu ada pengaruh positif dan signifikan kepemimpinan kepala sekolah, displin kerja secara bersama-sama terhadap kinerja guru dengan nilai determinasi 49.1\%. Artinya pengaruh kepemimpinan kepala sekolah, displin kerja guru terhadap kinerja guru SD di Korwil Pendidikan Kecamatan Klaten Selatan dapat dijelaskan sebesar $49.1 \%$ sedangkan $50.9 \%$ dipengaruhi oleh variabel lain yang tidak diteliti. Dari hasil uji t dapat disimpulkan bahwa variabel kepemimpinan kepala sekolah mempunyai koefisien korelasi parsial 0.146 nilai t hitung sebesar 1.846 dan nilai signifikansi sebesar 0,067>0,05, maka secara parsial hipotesis yang berbunyi terdapat pengaruh yang positif dan signifikan antara kepemimpinan kepala sekolah terhadap kinerja guru SD di Korwil Pendidikan Kecamatan Klaten Selatan ditolak.
\end{abstract}

Kata Kunci: kepemimpinan kepala sekolah, disiplin kerja,kinerja guru sd

\section{THE INFLUENCE OF THE PRINCIPAL'S LEADERSHIP AND WORK DISCIPLINE ON ELEMENTARY SCHOOL TEACHERS' PERFORMANCE IN KECAMATAN KLATEN SELATAN KABUPATEN KLATEN}

\begin{abstract}
This research was motivated by the influence of the principal's leadership and work discipline on elementary school teachers' performance in Kecamatan Klaten Selatan, Kabupaten Klaten. The method used in this study was a survey. The target in this study were elementary school teachers in Kecamatan Klaten Selatan, Kabupaten Klaten. The analysis technique in this study used the classical assumption test, multiple linear regression method, hypothesis testing and coefficient of determination test. The results of the study were that there was a positive and significant influence on principal leadership and work discipline on teachers ' performance with a determination value of $49.1 \%$. This means that the influence of the principal's leadership and teachers' work discipline on the performance of elementary school teachers in Kecamatan Klaten Selatan, Kabupaten Klaten. was explained by $49.1 \%$ while $50.9 \%$ was influenced by other variables. From the results of the t-test, this research concluded that the principal's leadership variable had a partial correlation coefficient of 0.146 , the t-count value of 1.846 and a significance value of $0.067>0.05$, then partially the hypothesis which read that there was a positive and significant influence between the principal's leadership on teachers' performance Elementary schools in the Education Coordinator of Kecamatan Klaten Selatan, Kabupaten Klaten.
\end{abstract}

Keywords: principals' leadership, work discipline, teachers' performance

\begin{tabular}{|c|c|c|}
\hline Submitted & Accepted & Published \\
\hline 07 Oktober 2021 & 17 November 2021 & 27 November 2021 \\
\hline
\end{tabular}

\begin{tabular}{|l|c|c|}
\hline Citation & $:$ & $\begin{array}{r}\text { Tukiyo, T. (2021). Pengaruh Kepemimpinan Kepala Sekolah, Disiplin Kerja, Terhadap Kinerja Guru SD Di Wilayah } \\
\text { Kecamatan Klaten Selatan Kabupaten Klaten. Jurnal PAJAR (Pendidikan dan Pengajaran), 5(6), 1807-1815. } \\
\text { DOI : http://dx.doi.org/10.33578/pjr.v5i6.8575. }\end{array}$ \\
\hline
\end{tabular}

\section{PENDAHULUAN}

Pendidikan adalah usaha sadar dan terencana untuk mewujudkan suasana belajar dan proses pembelajaran agar peserta didik secara aktif mengembang memiliki kekuatan spiritual keagamaan, pengendalian diri, kepribadian, kecerdasan, akhlak mulia, serta keterampilan yang diperlukan dirinya, masyarakat, bangsa dan negara. Menurut Sagala (2013 : 3) Pendidikan adalah proses mengubah tingkah laku peserta didik agar menjadi manusia dewasa yang mampu hidup mandiri dan sebagai anggota masyarakat dalam lingkungan alam sekitar 
dimana individu itu berada. Sehingga dalam melaksanakan prinsip penyelenggaraan pendidikan harus sesuai dengan tujuan pendidikan nasional yaitu; mengembangkan kemampuan dan membentuk watak serta peradaban bangsa yang bermartabat dalam rangka mencerdaskan kehidupan bangsa. Sebuah pendidikan biasanya diajarkan oleh seorang guru, dan biasanya lokasinya disekolah, namun sebenarnya pendidikan tak hanya dapat diberikan disekolah saja, pendidikan dapat kita dapatkan dimana saja. Guru merupakan seseorang yang perlu di gugu dan ditiru, artinya apabila kita menjadi sesosok guru, kita harus bersikap yang pantas agar murid-murid dapat mencontohnya dengan baik. Tugas utama seorang guru adalah mengajar. Howard dalam Asep Jihad (2013:9) "Mengajar adalah suatu aktivitas membimbing atau menolong seseorang untuk mendapatkan, mengubah, atau mengembangkan keterampilan, sikap (attitude), cita-cita (ideals), pengetahuan (knowledge) dan penghargaan(appreciation). Sumiati (2013:24) berpendapat bahwa : Mengajar adalah segala upaya yang disengaja dalam rangka memberikan kemungkinan bagi siswa untuk terjadinya proses belajar dengan tujuan yang telah dirumuskan. Jika diterima ini, sasaran akhir proses pembelajaran adalah siswa belajar. Oleh karena itu upaya apa pun dapat dilakukan, asalkan upaya itu disengaja dengan penuh tanggung jawab mengantarkan siswa menuju pencapaian tujuan. Tujuan itu dicapai melalui proses pembelajaran, sedangkan kemungkinan terjadinya proses belajar itu sendiri beraneka ragam. Bisa terjadi guru tampin didepan kelas. Mulai dari sikap terhadap murid, cara berbicara, sampai cara berpakaian, haruslah yang sesuai. Karena guru menjadi sorotan dikelas dan juga memiliki peran penting disekolah, maka dari itu guru harus memiliki kompetensi standar yang baik.

Rendahnya kualitas intelektual yang dimiliki guru diasumsikan oleh banyak orang dikarenakan minimnya penghasilan yang diterima oleh guru setiap bulannya dibandingkan dengan negara-negara lain. Sehingga untuk bisa menambah pengetahuan dan informasi lewat berbagai media kurang mampu dilakukan karena untuk mencukupi kebutuhan,guru tidak cukup dengan penghasilan yang minim. UU No 14 tahun
2005 tentang Guru dan Dosen, disebutkan bahwa setiap guru berhak memperoleh penghasilan di atas kebutuhan hidup minimum dan jaminan kesejahteraan sosial. Namun untuk memperoleh penghasilan yang lebih itu tidaklah mudah, karena hal tersebut hanya diberikan kepada guru yang telah memiliki sertifikat pendidik. Berbagai kiat dilakukan guru untuk meningkatkan profesionalismenya salah satunya dengan menempuh program PPG. Guru telah memiliki kompetensi untuk melaksanakan pelayanan pendidikan pada satuan pendidikan tertentu setelah uji kompetensi yang diselenggarakan oleh lembaga sertifikasi (UU RI nomor 14 tahun 2005).

Kesuksesan para guru tersebut seringkali tidak diikuti dengan keprofessionalan dalam mengajar, malah terkadang para guru yang telah lulus PPG kurang rajin dalam mengajar, hal ini dikarenakan mereka telah mempunyai gaji yang cukup sehingga mulai jarang untuk bekerja. Sekarang banyak dijumpai guru yang kurang profesional, hal tersebut dapat dilihat dari perilaku guru yang kurang pas semisal membolos pada jam pelajaran, jadwal mengajar dari guru yang tidak terencana,malas ketika hendak mengajar. Perilaku-perilkau tersebut menunjukkan kualitas guru yang rendah. Peran guru semakin penting dalam peningkatan di dunia pendidikan, maka perlu juga guru mendapatkan kepuasan kerjanya sehingga hal tersebut akan berdampak baik bagi displin kerja sehinggga akan menjadikan kinerja guru menjadi lebih baik. Sementara itu kompetensi yang baik akan berjalan seiring dengan displin kerja yang baik pula. Robbins (dalam Sudarto, 2012) menyatakan bahwa kepemimpina (kepala sekolah) merupakan faktor utama dari kepuasan kerja. Kepemimpinan merupakan norma, prilaku yang digunakan oleh seseorang pada saat orang tersebut mencoba mempengaruhi prilaku orang lain (dalam Nurmalinda, 2019). Lebih lanjut Zuryati (2015) meyatakan kepemimpinan merupakan cara berperilaku yang khas dari seorang pemimpin terhadap para anggota kelompoknya.

Kepemimpinan kepala sekolah memiliki fungsi strategis dalam pembangunan kinerja guru, tanpa contoh yang baik guru tidak dapat mengerjakan tugasnya dengan baik pula dan sesuai dengan yang rencana yang diharapkan 
sekolah. Guru dikatakan berperan apabila guru melakukan berbaga iaktivitas sesuai dengan tugasnya. Oleh karena itu, guru harus tahu persis apa yang menjadi tugas utamanya sehingga mutu pendidikan menjadi lebih baik (Jesica, 2019) Kenyataan dilapangan sekarang ini, peneliti menemukan guru bekerja sambilan sehingga fokus guru terbagi 2 dalam melaksanakan tugasnya, guru dalam menyampaikan materi ajar belum optimal, hal ini terlihat sewaktu guru mengajar tidak menggunakan alat peraga yang dapat mendukung proses pembelajaran, kurangnya tanggung jawab guru dalam mengajar, hal ini terlihat dari seringnya guru terlambat masuk kedalam kelas untuk mengajar serta kurangnya pembimbingan siswa dalam proses pembelajaran. Permasalahan yang peneliti temukan ini sejalan dengan permasalahan yang di kemukakan oleh Azmi (2019) yang sehingga materi yang diajarkan menurut keinginan dan kemauan guru saja, serta tidak jarang guru terlambat datang kesekolah. lebih lanjut, dirinya untuk menyatakan masih ada guru dalam mengajar tidak melengkapi perangkat pembelajaran.

\section{KAJIAN TEORETIS}

\section{Kepemimpiman kepala sekolah}

Kepemimpinan adalah sekumpulan dari serangkaian kemampuan dan sifat-sifat kepribadian, termasuk didalamnya kewibawaan, untuk dijadikan sebagai sarana dalam rangka meyakinkan yang dipimpinnya agar mereka mau dan dapat melaksanakan tugas-tugas yang dibebankan kepadanya dengan rela, penuh semangat, ada kegembiraan batin, serta merasa tidak terpaksa (Suharsaputra, 2010). Menurut (Wahjosumidjo, 2010), kata "memimpin" mempunyai arti memberikan bimbingan, menuntun, mengarahkan, dan berjalan di depan (precede). Pemimpin berperilaku untuk membantu organisasi dengan kemampuan maksimal dalam mencapai tujuan. Pemimpin tidak berdiri sendiri di samping, melainkan mereka memberikan dorongan dan memacu (to prod), berdirdepan yang memberikan kemudahan untuk kemajuan serta memberikan inspirasi organisasi dalam mencapai tujuan Kepemimpinan seseorang berperan sebagai penggerak dalam proses kerjasama antar manusia dalam organisasi termasuk sekolah..
Kepemimpinan dapat menentukan arah atau tujuan yang dikehendaki, dan dengan cara bagaimana arah atau tujuan tersebut dapat dicapai. Kepemimpinan kepala sekolah sangat besar sekali pengaruhnya terhadap kemajuan sekolah yang dipimpinnya karena merupakan ujung tombak bagi kemajuan sekolahnya. Untuk itu seorang kepala sekolah dituntut harus memiliki tingkat kinerja yang tinggi. Adapun peran dari kepala sekolah adalah sebaga berikut: (1) educator, (2) manager, (3) administrator, (4) supervisor , (5) leader, (6) inovator, dan (7) motivato (Depdiknas, 2006)

Sebagai pemimpin tertinggi di sekolah ada beberapa tugas yang harus dilaksanakannya, seperti: 1) membimbing guru untuk menyusun program pengajaran; 2) membimbing guru untuk melaksanakan program pengajaran yang telah dirancang; 3) membimbing guru untuk melaksanakan evaluasi hasil belajar siswa; 4) membimbing guru untuk melaksanakan program pengayaan dan remedial; 5) melakukan pengembangan guru melalui pendidikan dan pelatihan; 6) melakukan pengembangan guru melalui pertemuan sejawat; 7) melakukan pengembangan guru dengan mengikutkan guru dalam seminar, diskusi, dan sejenisnya; 8) mengusulkan kenaikan pangkat guru secara periodic; dan 9) mengikuti perkembangan iptek melalui pendidikan dan pelatihan (Nurmalinda, 2019).

\section{Kinerja Guru}

adalah prestasi kerja seorang pendidik (tenaga profesional) yang dapat dilakukan melalui aktivitas, prilaku dan produktifitas yang sesuai dengan tugas dan tanggung jawab yang diembannya. (Marlina, 2019). Beberapa faktor yang mempengaruhi kinerja guru yang dirangkum dalam buku Etika Profesi Keguruan oleh Ondi Saondi dan Aris Suherman, antar lain: a), Kepribadian dan dedikasi. b) Pengembangan profesi c) Kemampuan mengajar, c) Komunikasi d) Hubungan dengan masyarakat e) Kedisiplinan f) Kesejahteraan g) Iklim kerja.(Marlina, 2019) Kinerja merefleksikan kesuksesan suatu organisasi, maka dipandang penting untuk mengukur karakteristik tenaga kerjanya. Kinerja dapat dilihat dari beberapa kritreria. Menurut Castetter mengemukaan 
empat kriteria kinerja, yaitu karakteristik individu, proses, hasil dan kombinasi antara karakter individu, proses dan hasil.Menempatkan seorang guru dalam mengajar harus disesuaikan dengan keahliannya, hal tersebut akan berpengaruh terhadap kinerjanya. Apabila tugas yang diberikan tidak sesuai dengan pekerjaannya akan berakibat menurunnya kinerja, baik cara kerja maupun hasil kerjanya.(Marlina, 2019).

\section{METODE PENELITIAN}

Penelitian ini adalah termasuk penelitian survey. Menurut Sugiyono (2013:11) Penelitian survey adalah Penelitian yang dilakukan dengan menggunakan angket sebagai alat penelitian yang dilakukan pada populasi besar maupun kecil, tetapi data yang dipelajari adalah data dari sampel yang diambil dari populasi tersebut sehingga ditemukan kejadian relatif, distribusi, dan hubungan antar variabel, sosiologis maupun psikologis. Adapun desain penelitian ini menggunakan pendekatan kuantitatif, karena data yang diperoleh berupa angka-angka dan pengolahannya menggunakan metode statistik yang kemudian hasilnya diinterpretasikan. Sasaran dalam penelitian ini adalah guru-guru SD Negeri yang mengajar di wilayah Kecamatan Klaten Selatan, Kabupaten Klaten. Metode yang digunakan dalam penelitian ini adalah survey. Populasi penelitian ini adalah 18
SD Negeri dan 5 SD Swasta di Korwil Pendidikan Kecamatan Klaten Selatan.

Pengambilan sampel menggunakan teknik Quota Random Sampling dimana pengambilan anggota sampel secara acaak tanpa memperhatikan strata yang ada dalam populasi tersebut. Endang Mulyatiningsih (2011:10) menyebutkan bahwa sampel yang diambil harus mewakili semua karakteristik yang terdapat pada populasi dimana kesimpulan tersebut akan berlaku. Teknik penentuan jumlah sempel yang digunakan dalam penelitian ini mengacu pada tabel omogram Harry King dengan dasar tingkat kesalahan 5\% memiliki tingkat kepercayaan 95\% terhadap populasi. Jumlah populasi pendidik pada Korwil Pendidikan Kecamatan Klaten selatan 321 orang, maka sampel yang diambil : $0.42 \times 321 \times 1.195=161$ orang.

\section{HASIL DAN PEMBAHASAN \\ Hasil Penelitian}

Dari perhitungan analisis deskriptif dengan bantuan program SPSS versi 24.0 for windows diperoleh hasil skor sebagai berikut $\mathrm{N}=$ 161 : nilai mean $=81.84$, median $=82$ mode $=81$ std deviation $=5.655$ minimum $=65$, maximum $=$ 95 sum $=13.176$. Hasil frekwensi data variabel Kepemimpinan kepsek guru lebih jelasnya dapat dilihat pada gambar histogram sebagai berikut:

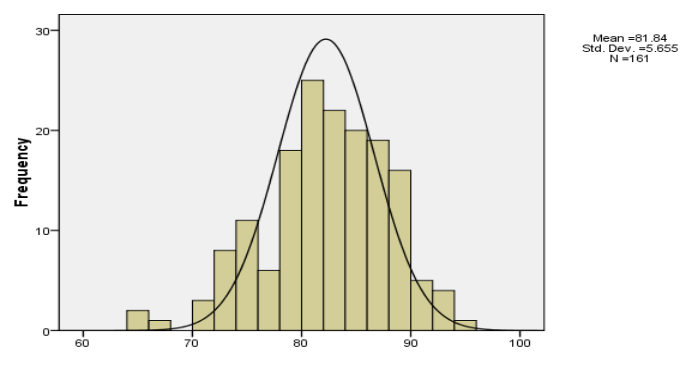

\section{Gambar 1. Histogram Variabel Kepemimpinan Kepsek}

Dari perhitungan analisis deskriptif dengan bantuan program SPSS versi 24.0 for windows diperoleh hasil skor sebagai berikut $\mathrm{N}=$ 161 , :nilai mean $=82.77$, median $=83$. mode $=80$ std deviation $=5.088$, minimum $=65$ maximum $=$ 95 sum $=13.176$. . Hasil frekwensi data variabel disiplin kerja guru lebih jelasnya dapat dilihat pada gambar histogram sebagai berikut 


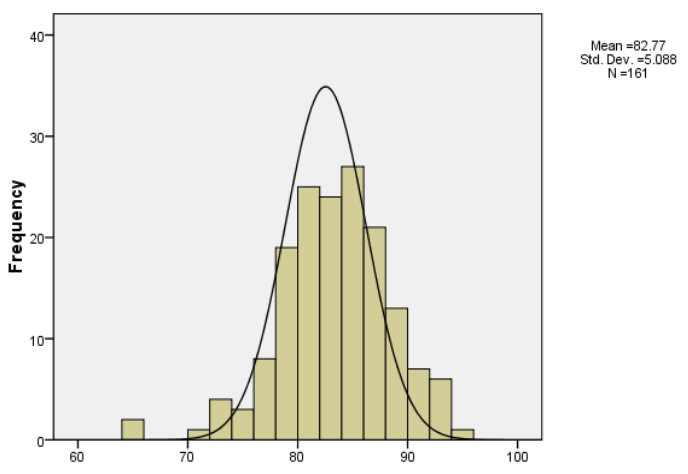

Gambar 2. Histogram Variabel Disiplin Kerja Guru

Dari perhitungan analisis deskriptif dengan bantuan program SPSS versi 24.0 for windows diperoleh hasil skor sebagai berikut $\mathrm{N}=$ 161 , :nilai mean $=81,50$, median $=82$, mode $=78$ std deviation $=5,945$, minimum $=65$, maximum $=$ 98 , sum $=13.121$. Hasil frekwensi data variabel kinerja guru lebih jelasnya dapat dilihat pada gambar histogram sebagai berikut :

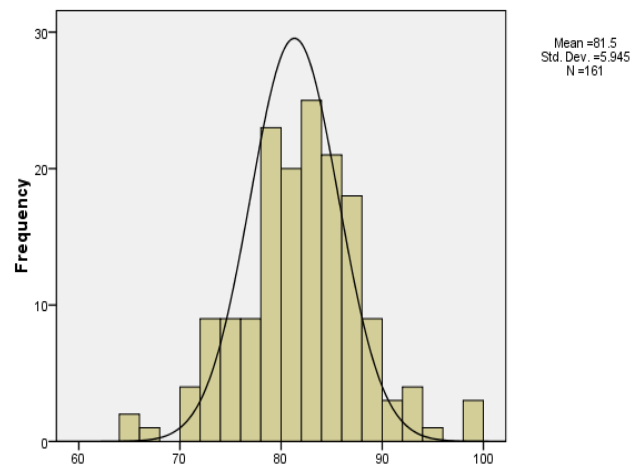

Gambar 3. Histogram Variabel Kinerja Guru

Uji normalitas bertujuan untuk menguji apakah dalam model regresi mempunyai distribusi sebaran data normal atau tidak. Hasil analisis uji normalitas menggunakan bantuan program SPSS for windows 24.0 dapat dilihat dari rangkuman sebagai berikut:

Tabel 4. Rangkuman Hasil Kolmogorov-Smirnov

\begin{tabular}{|c|c|c|c|}
\hline Variabel & Statistic & $\begin{array}{l}\mathbf{P} \\
\text { Value }\end{array}$ & Kesimpulan \\
\hline $\begin{array}{l}\text { Kepemimpinan } \\
\text { Kepsek (X1) }\end{array}$ & 0.068 & 0.069 & $\begin{array}{c}\text { Data } \\
\text { Berdistribusi } \\
\text { Normal }\end{array}$ \\
\hline Disiplim Kerja & 0.068 & 0.065 & $\begin{array}{c}\text { Data } \\
\text { berdistribusi }\end{array}$ \\
\hline Guru (X2) & & & Normal \\
\hline $\begin{array}{l}\text { Kinerja Kerja } \\
\text { Guru (Y) }\end{array}$ & 0.065 & 0.098 & $\begin{array}{c}\text { Data } \\
\text { Berdistribusi } \\
\text { Normal }\end{array}$ \\
\hline
\end{tabular}


Berdasarkan tabel 4 ringkasan hasil uji Normalitas diatas, data Kinerja guru (Y), data kepemimpinan kepala sekolah $\left(\mathrm{X}_{1}\right)$, data Disiplin kerja $\left(\mathrm{X}_{2}\right)$, semuanya Pvalue $>0.05$ maka dapat disimpulkan bahwa data variabel bebas $\left(\mathrm{X}_{1}\right),\left(\mathrm{X}_{2}\right)$, dan data variabel terikat $(\mathrm{Y})$ berdistribusi normal sehingga dapat dilakukan analisis regresi berganda.

\section{Pembahasan}

Uji linieritas merupakan pengujian garis regresi antara variabel bebas dengan variabel tergantung. Tujuan dari linieritas peneitian ini adalah untuk memastikan bahwa terdapat hubungan yang linier antara variabel $\mathrm{x}$ dengan $\mathrm{y}$. Suatu hubungan dapat dikatakan linier apabila sebaran nilai variabel-variabel penelitian ini berada dalam satu garis lurus.

Tabel 5. Rangkuman Hasil F Deviation From Linierty

$\begin{array}{llll}\text { Variabel } & \text { F } & \text { P } & \text { Kesimpulan }\end{array}$

Deviation

FL

\begin{tabular}{llll}
\hline KG -Kep, kepsek & 1.560 & 0.059 & Linier \\
KG - Disiplin K & 1.604 & 0.051 & Linier \\
\hline
\end{tabular}

Dari tabel diatas dapat disimpulkan bahwa hubungan kinerja guru (Y), terhadap kepemimpinan kepala sekolah $\left(\mathrm{X}_{1}\right)$, kinerja guru terhadap disiplin kerja guru $\left(\mathrm{X}_{2}\right)$, mempunyai Pvalue $\geq 0.05$ maka dapat menunjukkan kedua hubungan tersebut bersifat linier

Uji multikoloniaritas bertujuan untuk menguji apakah model regresi ditemukan adanya korelasi yang sempurna antar variabel bebas. Model regresi yang baik seharusnya tidak terjadi korelasi yang sempurna di antara variabel bebas. Salah satu cara untuk mendeteksi adanya multikolonieritas adalah dengan melihat torerance atau Varians Inflation Factor (VIF). Apabila tolerance lebih kecil daril atau VIF di atas 10, maka terjadi multikoloniaritas.

\section{Tabel 6. Rangkuman Hasil Uji Multikoloniaritas}

\begin{tabular}{lccl}
\hline Variabel & Tolerance & VIF & \multicolumn{2}{c}{ Kesimpulan } \\
\hline $\begin{array}{l}\text { Kepemimpinan } \\
\text { Kepsek (X1) }\end{array}$ & 0.852 & 1.173 & $\begin{array}{l}\text { Tidak terjadi } \\
\text { Multikoloniaritas }\end{array}$ \\
$\begin{array}{l}\text { Disiplin Kerja } \\
\text { Guru (X2) }\end{array}$ & 0.785 & 1.274 & $\begin{array}{l}\text { Tidak terjadi } \\
\text { Multikoloniaritas }\end{array}$ \\
\hline
\end{tabular}

Berdasarkan ringkasan hasil uji multikoloniaritas diatas, Kepemipinan Kepala Sekolah (X1), Displin Kerja Guru (X2), semuanya nilai tolerance $\geq 0,10$ dan nilai Varians Inflation Factor (VIF) $\leq 10$, maka dapat disimpulkan bahwa kedua variabel bebas Kepemipinan Kepala Sekolah (X1), Displin Kerja Guru (X2) tidak terjadi multikooniaritas.

Pengujian hipotesis dalam penelitian ini menggunakan regresi linier berganda, analisis ini dimaksudkan untuk mengetahui pengaruh variabel-variabel bebas (independen) terhadap variabel terikat (dependen). Terdapat pengaruh yang positif dan signifikan antara kepemimpinan kepala sekolah, dispin kerja guru secara bersamasama terhadap kinerja guru SD di Korwil Pendidikan Kecamatan Klaten Selatan, hal ini dapat dijelaskan dari rangkuman tabel berikut: 


\begin{tabular}{cccccc}
\multicolumn{5}{c}{ Tabel 7. Rangkuman Hasil Analisis Model Summary } \\
R & R S & F & P & K \\
$\overline{0.491}$ & $\overline{0.241}$ & $\overline{16.651}$ & $\overline{0.000}$ & $\overline{\text { Berpengaruh }}$
\end{tabular}

Dari hasil uji $\mathrm{F}$ yang terdapat pada tabel 4.5 nilai $\mathrm{R}$ sebesar 0,491 dengan nilai $\mathrm{F}$ sebesar 16.651 dan nilai signifikansi sebesar 0.000 lebih kecil dari 0.05. Maka dapat disimpulkan bahwa Hipotesis yang berbunyi " Terdapat pengaruh yang positif dan sangat signifikan kepemimpinan kepala sekolah, disiplin kerja guru secara bersama-sama terhadap kinerja guru SD di Korwil pendidikan Kecamatan Klaten Selatan " di terima. Untuk mengetahui seberapa besar pengaruh variabel independen (Kepemimpinan Kepala Sekolah, Disiplin Kerja Guru) terhadap variabel dependen (Kinerja Guru SD ) dapat dilihat dari nilai koefisien determinasi ( $R$ Square).

Tabel 8. Unstandardized coefficient

\begin{tabular}{llc}
\hline & \multicolumn{2}{c}{ Unstandardized coefficients } \\
& $\mathrm{B}$ & Std.Error \\
Constant v & 32.644 & 7.812 \\
\hline Kep,kepsek & 0.134 & 0.072 \\
Displin Kerja & 0.393 & 0.079 \\
Guru & & \\
\hline
\end{tabular}

Terdapat pengaruh yang positif dan signifikan antara kepemimpinan kepala sekolah terhadapa kinerja guru SD di Korwil Pendidikan
Kecamatan Klaten SelatanDapat dijelaskan dengan melihat koefisien korelasi dan signifikansinya seperti pada tabel di bawah ini :

Tabel 9. Rangkuman hasil Koefisien Korelasi Parsial

\begin{tabular}{|c|c|c|c|c|c|}
\hline \multirow[t]{2}{*}{ Variabel } & \multicolumn{2}{|c|}{ Correlations } & \multirow[t]{2}{*}{ thitung } & \multirow[t]{2}{*}{ sig } & \multirow[t]{2}{*}{ Kesimpulan } \\
\hline & $\begin{array}{l}\text { Zero- } \\
\text { order }\end{array}$ & Partial & & & \\
\hline Constant & & & 4.179 & 0.000 & \\
\hline $\begin{array}{l}\text { Kepemimpinan Kepala } \\
\text { Sekolah }\end{array}$ & 0.283 & 0.146 & 1.846 & 0.067 & signifikan \\
\hline Disiplin Kerja Guru & 0.463 & 0.368 & 4.953 & 0.000 & $\begin{array}{l}\text { sangat } \\
\text { signifikan }\end{array}$ \\
\hline
\end{tabular}

Dari hasil uji t yang terdapat pada tabel 9 dapat disimpulkan bahwa variabel kepemimpinan kepala sekolah mempunyai koefisien korelasi parsial 0.146 nilai thitung sebesar 1.846 dan nilai signifikansi sebesar 0.067>0.05, maka secara parsial hipotesis yang berbunyi terdapat pengaruh yang positif dan signifikan antara kepemimpinan kepala sekolah terhadap kinerja guru SD di
Korwil Pendidikan Kecamatan Klaten Selatan ditolak..

Terdapat pengaruh yang positif dan signifikan displin kerja guru dan kinerja guru SD di Korwil Pendidikan Kecamatan Klaten Selatan. Dari hasil uji $t$ yang terdapat pada tabel 9 dapat disimpulkan bahwa variabel produktitvitas guru mempunyai koefisien korelasi parsial 0.368 nilai $\mathrm{t}$ hitung 4.953 dan nilai signifikansi $0.000<0.05$, 
maka secara parsial hipotesis yang bunyinya terdapat pengaruh yang positif dan signifikan produkttivitas guru terhadap kepuasan kerja guru di terima. Artinya dispiln kerja guru SD tidak dapat menjelaskan pengaruhnya terhadap kinerja kerja guru SD. Koefisien korelasi Zero- order 0.463 dan setelah dikendalikan oleh variabel lain koefisien korelasi 0.368 terjadi penurunan koefisien, karena pengaruh displin kerja guru SD terhadap kinerja guru dikendalikan oleh variabel kepemipinan kepala sekolah dan disiplin kerja guru.

\section{Sumbangan Prediktor}

Sumbangan prediktor digunakan untuk mengetahui berapa sumbangan (kontribusi) masing-masing variabel bebas.

\begin{tabular}{|c|c|c|c|}
\hline Variabel & $\beta$ & rxy & $\begin{array}{c}\mathrm{R} \\
\text { square }\end{array}$ \\
\hline $\begin{array}{l}\text { Kepemimpinan } \\
\text { kepala sekolah }\end{array}$ & 0.139 & 0.283 & 0.241 \\
\hline $\begin{array}{l}\text { Disiplin } \\
\text { Kerja guru }\end{array}$ & 0.389 & 0.463 & \\
\hline
\end{tabular}

1. Sumbangan Efektif

a). Sumbangan efektif kepemimpinan kepela sekolah

$$
\begin{aligned}
\mathrm{SE}(\mathrm{X} 1) \% & =\beta \mathrm{x} 1 \mathrm{X} \mathrm{rx} 1 \mathrm{y} \times 100 \% \\
& =0.139 \times 0.283 \times 100 \% \\
& =3.93 \%
\end{aligned}
$$

Sumbangan efektif disiplin kerja guru $\mathrm{SE}(\mathrm{X} 2) \%=\beta \times 2 \times \mathrm{x} \times 2 \mathrm{y} \times 100 \%$ $=0.389 \times 0.463 \times 100 \%$ $=18.01 \%$

$\mathrm{SE}$ total $=\mathrm{SE}(\mathrm{X} 1) \%+\mathrm{SE}(\mathrm{X} 2) \%$

$$
\begin{aligned}
& =3.3 \%+18.01 \% \\
& =21.94 \% \approx 22 \%
\end{aligned}
$$

2.Sumbangan Relatif

a). Sumbangan relatif kepsek

$\mathrm{SR}(\mathrm{X} 1)=\mathrm{SE}(\mathrm{X} 1) \%$

$$
\begin{aligned}
& \mathrm{R}_{\frac{\mathrm{X}}{2} \mathrm{X} 100 \%} \\
= & 3.93 / 22 \% * 100 \% \\
= & 17.8 \%
\end{aligned}
$$

b) Sumbangan relatif disiplin kerja guru

$$
\begin{aligned}
\mathrm{SR}(\mathrm{X} 1) & =\mathrm{SE}(\mathrm{X} 2) \% \\
& \mathrm{R}^{2} \mathrm{X} 100 \% \\
= & 18.01 / / 22 * 100 \% \\
= & 81.86 \% \\
& =\mathrm{SR}(\mathrm{X} 1) \%+\mathrm{SR}(\mathrm{X} 2) \% \\
& =17.8 \%+81.86 \% \\
\text { SR total } & \approx 99.66 \%=100 \%
\end{aligned}
$$

\section{SIMPULAN DAN REKOMENDASI}

Hasil penelitian ini diperoleh pengaruh positif dan signifikan, sehingga memperkuat konsep bahwa kinerja guru SD dipengaruhi oleh faktor-faktor kepemimpinan kepala sekolah, disiplin kerja guru. Dari hasil tersebut dapat disimpulkan sebagai berikut:

1. Kepemimpinan kepala sekolah mempunyai pengaruh positif tetapi tidak signifikan terhadap kinerja guru dengan sumbangan efektif 3,93\%. Kepemimpinan merupakan suatu proses penggunaan pengaruh positif terhadap orang lain untuk melakukan usaha lebih banyak dalam sejumlah tugas atau mengubah perilakunya. Kepemimpinan kepala sekolah tidak berpengaruh signifikan terhadap kepuasan kerja guru SD disebabkan karena (1) Tidak adanya kemauan/dorongan kepala sekolah yang kuat dengan penuh semangat dan percaya pada guru, staff, dan siswa dalam melaksanakan tugas masing-masing. (2) Kepala sekolah tidak memberikan bimbingan dan mengarahkan pada guru, staff dan para siswa serta memberikan dorongan, memacu dan berdiri di depan demi kemajuan dan memberikan inspirasi sekolah dalam mencapai tujuan(3) Kepala sekolah tidak mampu untuk memberikan sugesti atau saran yang diperlukan oleh para bawahan dalam melaksanakan tugas.(4) Kepala sekolah kurang mampu untuk menciptakan rasa aman dalam lingkungan 
sekolah. (5) Dalam kepemimpinannya kepala sekolah bertindak kasar/seenaknya sebdiri sehingga menyebabkan guru, dan staff tidak bisa untuk mencapai kepuasan kerja

2. Terdapat pengaruh yang positif dan tidak signifikan Disiplin kerja guru dan kinerja guru SD di Korwil Pendidikan Kecamatan Klaten Selatan. Disiplin kerja guru merupakan faktor yang dapat mempengaruhi kinerja guru. Dari faktor-faktor tersebut diatas apabila salah satu faktor tidak terpenuhi seperti disiplin kerja guru maka faktor yang lain akan mepengaruhi terhadap kinerja guru tersebut Dalam artian displin kerja hanya berpengaruh kecil terapi disiplin kerja tetap akan tercapai dengan baik.

3. Kepala sekolah dalam kepemimpinannya harus dapat menempatkan guru sesuai dengan keterampilan dan kompetensinya agar dapat berprestasi, serta menjaga lingkungan kerjanya sehingga tercipta rasa aman,nyaman serta kondusif. Disiplin kerja hanya sebagian kecil memepengaruhi kinerja guru. Hal itu disebabkan karena adanya loyalitas pegawai itu sendiri. Jadi kepemimpinan, Disiplin mempengaruhi kinerja kerja.

\section{DAFTAR PUSTAKA}

Azmi. (2019). Meningkatkan Disiplin Guru dalam Kehadiran ke Sekolah dan Mengajar di Kelas Melalui Penerapan "Reward and Punishment". Jurnal PAJAR (Pendidikan dan Pengajaran), 3 (3), 550-559.

Jesica, L., Witri, G., \& N. Lazim. (2019). Hubungan Pengelolaan Kelas Dengan Hasil Belajar Matematika Siswa Kelas V.

Sagala, S. (2013). Konsep dan Makna Pembelajaran. Bandung: Alvabeta SD SeGugus I Kecamatan Marpoyan Damai Pekanbaru. Jurnal Pajar ( Pendidikan dan Pengajaran, 3 (1), 87-92

Marlina, M. (2019). Studi Korelasi Disiplin Dalam Pembelajaran Dengan Kinerja Guru. Jurnal Pajar (Pendidikan dan Pengajaran), 6 (1), 45-49

Sudarto. (2012). Pengaruh Pola Kepemimpinan Kepala Sekolah dan Suasana Kerja terhadap Kinerja Guru. Online.https://sudharto.blogspot.com/201 2.
Sumiati, I. (2006). Statistik. Bandung: Alfabeta. Sugiyono. (2013). Metode Penelitian Kuantitatif, Kualitatif dan $R \& D$. Bandung: Alfabeta. CV

Suharsaputra, U. (2010). Administrasi Pendidikan. Bandung: PT Refika Aditama.

Nurmalinda. (2019). Pengaruh Gaya Kepemimpinan Kepala Sekolah Terhadap Kinerja Guru di SD Negeri 003 Benai Kecil. Jurnal PAJAR (Pendidikan dan Pengajaran), 3 (3), 607-614.

Wahjosumidjo. (2010). Kepemimpinan dan Motivasi. Jakarta: Ghalia Indonesia.

Zuryati., Djailani, A.R., \& Usman, N. (2015). Gaya Kepemimpinan Kepala Sekolah Dalam Meningkatkan Kinerja Guru pada SDN 7 Muara Dua Lhoksuemawe. Jurnal Administrasi Pendidikan, 3(2), 38-48. 